\title{
O layout de materiais didáticos para a EAD: procurando parâmetros de editoração
}

\author{
The layout of materials for distance education: looking for publishing parameters
}

\author{
Dorcas Weber, Lia Raquel Oliveira \\ Universidade do Minho, Universidade do Minho
}

\begin{abstract}
Resumo
Estudos que rondam a temática dos materiais didáticos desenvolvidos para cursos a distância têm crescido desde a inserção desta modalidade no ensino superior. No Brasil, as primeiras experiências neste contexto estão às beiras de completar duas décadas. Ao longo deste período muitas linhas e objetos de pesquisa despontaram no âmbito da investigação acadêmica, uma delas envolve os materiais didáticos. Sua produção e uso restritos aos contextos de desenvolvimento fazem despertar a curiosidade em observar os modos de como vêm sendo organizados tais materiais e as possíveis semelhanças entre as produções.
\end{abstract}

Palavras chave: Educação a distância, Materiais didáticos, Layout.

\begin{abstract}
Studies that surround the theme of didatic materials developed for distance education courses have grown since the inclusion of this modality in higher education. In Brazil, the first experiments in this context are near to complete two decades. During this period many research topics emerged within the academic research, one of them is didatic materials. Their production and use restricted to development contexts make curiosity grow about the modes how the materials had been organized and if there are similarities between the productions.
\end{abstract}

Keywords: Distance education, Didatic materials, Layout.

\section{Introdução}

O inicio deste século foi marcado pelo aumento na oferta de opções no Ensino Superior brasileiro a partir de incentivos do governo para a realização de formação na modalidade a distância. No inicio, esta modalidade foi vista com descrédito por aqueles que pouco conheciam sobre esta modalidade, mas, pouco a pouco têm ganhado adeptos e despontado como uma opção a mais para aqueles que desejam alcançar formação superior. Com isso, novos campos profissionais e de investigação acabaram por surgir a partir das especificidades e necessidades que foram sendo desveladas ao longo das quase duas décadas.

Mediada pelas Tecnologias da Informação e Comunicação (TIC), a Educação a Distância (EAD) têm na internet uma aliada para os processos de mediação entre professores e alunos. Porém, será a mediação pela internet o bastante? Esta tecnologia é apenas um aspecto importante que permite a comunicação síncrona e/ou assíncrona e mais eficaz do que as tecnologias utilizadas nas primeiras experiências de EAD, tais como o correio, a rádio e a TV. Com a internet surge também a possibilidade de criar ambientes e integrar diferentes linguagens nos processos de comunicação entre professores e alunos. Neste contexto, destacam-se os materiais desenvolvidos e utilizados para a efetividade dos processos de ensino e aprendizagem. São eles que, de fato, fazem a mediação entre professores e alunos na EAD. Materiais didáticos, são produções conhecidas por quase todos, afinal, estiveram ou estão presentes de algum modo no cotidiano de todos que passaram pelos bancos escolares. No ensino presencial, onde são amplamente utilizadas, tais produções trazem em si os conhecimentos necessários ao aluno e que serão mediados pelo professor em um momento face a face. No contexto da EAD, os momentos não ocorrem face a face, contudo, o diálogo precisa acontecer e os conhecimentos necessitam ser aprendidos pelos alunos. Assim, na EAD, os materiais apresentam mais do que conteúdos, eles são mediadores dos diálogos e, além de apresentar elementos de conteúdo, atuam como comunicadores, instrutores e organizadores nos processos pedagógicos. Neste sentido, é importante compreender como são organizados e como se apresentam visualmente, os materiais didáticos, de modo que auxiliem nos processos de ensino e aprendizagem. Em busca de sanar tais inquietações, buscou-se por materiais utilizados em cursos de ensino superior brasileiros com vistas à encontrar semelhanças que possam, talvez, caracterizar parâmetros de editoração em materiais didáticos da EAD.

\section{Produções observadas}

Para realizar a observação utilizou-se como amostra três (03) materiais didáticos produzidos por instituições e disciplinas distintas. Foram selecionadas, nestas amostras, algumas páginas consideradas padrão, que apresentam estrutura recorrente e, a partir delas, buscados elementos comuns nas produções de modo que possam ser considerados parâmetros de organização.

\section{Material A - (Brennand \& Rossi, 2007)}

Desenvolvido para a disciplina "Matemática Instrumental” com carga horária de 60horas/aula, ofertada na Universidade Federal da Paraíba (UFPB) em 2009. Tal material foi observado na versão digital em 
formato PDF (Portable Document Format) e compunha de setenta e quarto (74) páginas em tamanho A4 que, segundo informações da coordenação do curso, teve uma versão impressa idêntica, à qual não se teve acesso. O material observado é parte integrante de um volume único no qual estavam agrupados vários materiais de diferentes disciplinas correspondentes a oferta semestral de um curso específico do qual optou-se observar apenas disciplina. As informações relacionadas à ficha catalográfica e sumário integram o volume único e, por isso, não constam na parte observada.

Partes que compõe o material: capa, apresentação do material, mapa conceitual da disciplina, croqui de curso, tabela de desempenho de percurso, unidade (cada unidade é estruturada com partes denominadas aulas nas quais podem ser observados textos e desafios/atividades).

Descrição dos elementos de editoração das páginas: Capa (figura 1) - Na parte superior esquerda, nota-se a identificação da instituição na qual o material foi desenvolvido; logo abaixo, no lado direito, o título da disciplina e a autoria do material; na parte inferior, centralizado, aparece a logomarca do curso ao qual o material pertence; ao fundo da página formas criam uma composição visual que configuram e identificam a capa; atenta-se a questão da utilização do fundo branco, formas e letras em uma escala de valores do preto. Na página inicial de unidade (figura 2) notam-se, no canto superior esquerdo e inferior direito, linhas pontilhadas que marcam uma margem na página; na parte superior há uma seqüência de retângulos nos quais estão identificadas unidades, na linha superior, e aulas, na linha inferior, caracterizando um menu de hiperlinks no qual dois retângulos aparecem com fundo acinzentado indicando ao leitor em qual parte do texto se encontra; logo abaixo a indicação da unidade pela numeração e pelo título; a seguir, a indicação da aula por número e título; abaixo encontra-se o texto a ser estudado; na parte inferior esquerda aparece o número de página, o título do material e da disciplina correspondente. Página aleatória de unidade (figura 3) - Observa-se a presença das linhas pontilhadas marcadoras de margem no canto superior direito e inferior esquerdo; na parte superior tem-se o menu indicativo, explicitado anteriormente, de unidades e aulas; ao longo da faixa de texto estão em evidência uma parte do texto com o uso de formas com fundo acinzentado, um box com indicativo de desafio, também com fundo acinzentado e figuras icônicas que indicam o "desafio"; além disso, há no final do texto, canto inferior direito um box com informações acerca de vídeoaulas assinalada por uma figura icônica; ao final, na parte inferior direito há o número de página e a logomarca do curso correspondente.

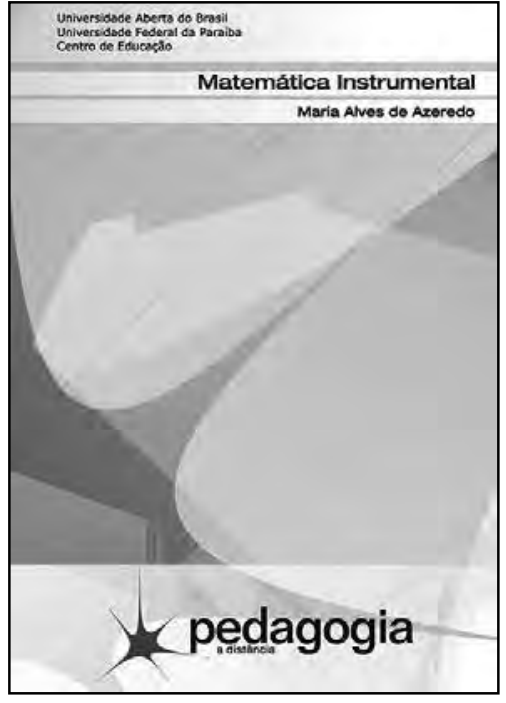

Figura 1. Material A (capa)

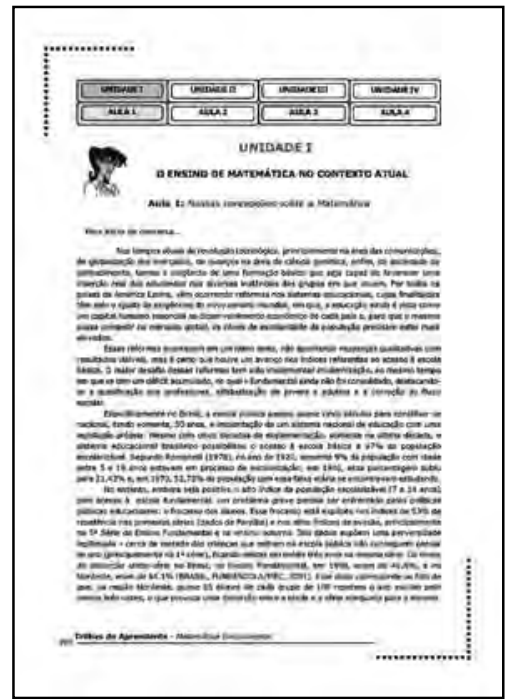

Figura 2. Material A (página inicial de unidade)

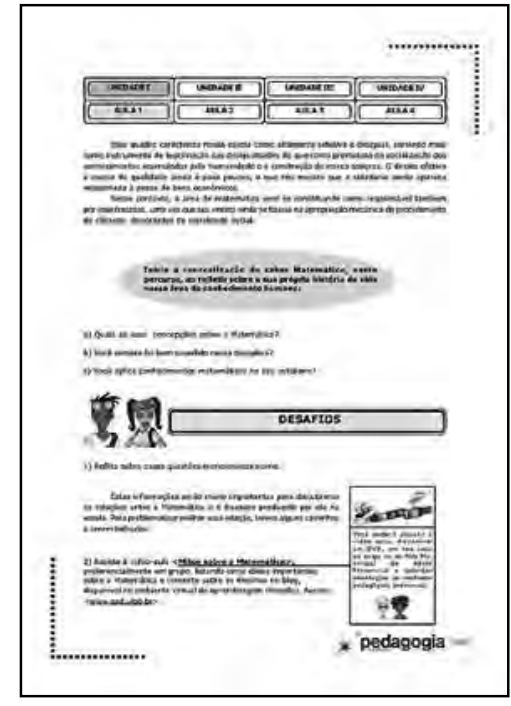

Figura 3. Material A (página aleatória) 


\section{Material B - (Silva, 2007)}

Elaborado para a disciplina "Psicologia e Educação" com carga horária de 60horas/aula, ofertada na Universidade do Sul de Santa Catarina (UnisulVirtual) produzido em 2007. O material observado caracteriza-se por um livro impresso com cento e sessenta e cinco (165) páginas em tamanho A4, denominado pela própria instituição de "livro didático".

Partes que compõe o material: capa, apresentação do material, ficha catalográfica, sumário, introdução à disciplina, plano de estudos, unidades (cada unidade é estruturada com: objetivos, seções, atividades e síntese), conclusão, referências e respostas.

Descrição dos elementos de editoração das páginas: Capa (figura 4) - Na parte superior nota-se a identificação da instituição na qual o material foi desenvolvido; centralizado na página está o título do material e a indicação de caracterizar-se por uma disciplina a ser realizada na modalidade a distância; na parte inferior, centralizado, aparece a logomarca do curso ao qual o material pertence; ao fundo da página formas, em tons de azul, criam uma composição visual para a capa, sobrepostas com palavras em cor branco. Página inicial de unidade (figura 5) - No lado direito, uma faixa que se estende da parte superior até a inferior, em tom cinza, na qual está a numeração correspondente a unidade; no canto superior esquerdo da página há o indicativo da unidade e logo a seguir, abaixo, o título correspondente; em seguida o texto, estruturado com títulos das partes que o organizam em fonte em tamanho maior e na opção negrito acompanhadas de figuras icônicas. Página aleatória de unidade (figura 6) - No canto superior direto encontra-se o nome da disciplina seguida de um fio que se estende de um lado a outro; no corpo da página observa-se o uso de imagens ilustrativas que complementam o texto, seguida de suas fontes; os textos estão alinhados justificados à esquerda; na parte inferior direita, no texto, nota-se um parágrafo em destaque acompanhado de figura icônica e com linhas na parte superior e inferior que demarcam e destacam o trecho; ao final, na parte inferior direito, há o número de página e o indicativo de unidade.

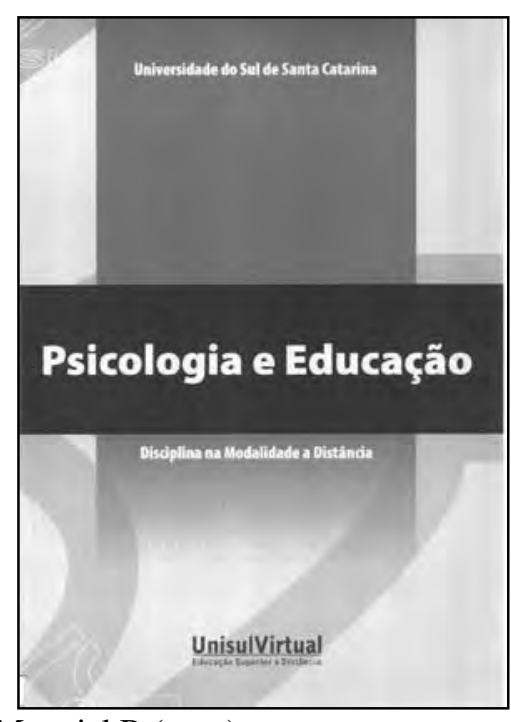

Figura 4. Material B (capa)

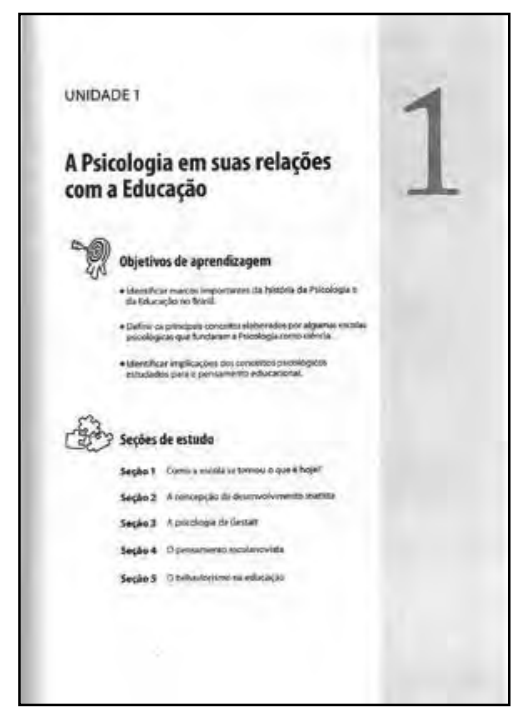

Figura 5. Material B (página inicial de unidade)

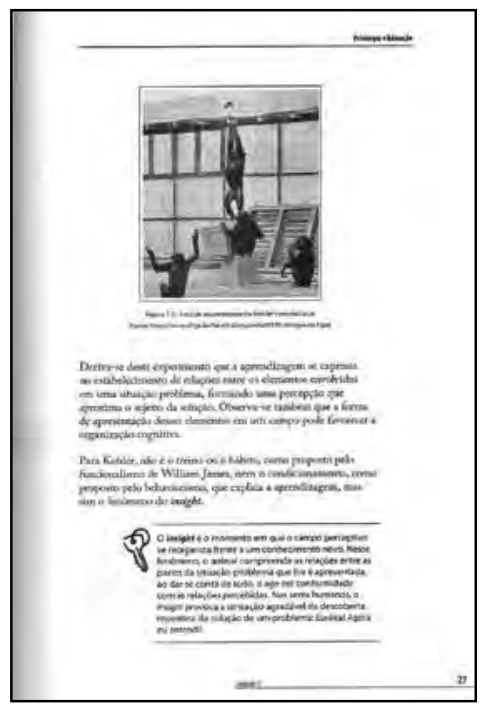

Figura 6. Material B (página aleatória) 
Material C - (SEAD/UFRGS, 2007)

Desenvolvido para a disciplina "Instrumentalização para o Ensino a Distância”, com carga horária de 60horas/aula, ofertada na Universidade Federal do Rio Grande do Sul (UFRGS) no ano de 2007. O material observado caracterizou-se por uma versão impressa e outra digital (PDF), idênticas, com o somatório de setenta (70) páginas em tamanho $25 \mathrm{~cm} \mathrm{x} \mathrm{17,5} \mathrm{cm.}$

Partes que compõe o material: capa, ficha catalográfica, sumário, lista de figuras, introdução, unidade (cada unidade é estruturada com: introdução, objetivos, textos, atividades e bibliografia).

Descrição dos elementos de editoração das páginas: Capa (figura 7) - Na parte superior esquerda encontra-se o título do material e autoria; na parte inferior esquerda uma logomarca indicativa da série à qual pertence o material; e, no canto inferior direito nota-se a identificação da instituição onde o material foi desenvolvido; ao fundo da página formas criam uma composição visual, em tons de verde, que constituem a capa. Página inicial de unidade (figura 8) - Na parte superior direita nota-se o número de página juntamente da logomarca da série da qual o material faz parte; na parte superior esquerda observa-se o título e numeração da unidade; a seguir, no corpo do texto estão destacados os títulos das partes com o uso de letras maiúsculas e em negrito, um box com um lembrete está integrado ao texto. Página aleatória de unidade (figura 9) - Na parte superior esquerda nota-se o número de página juntamente da logomarca da serie da qual o material faz parte; o corpo do texto no qual estão destacados os títulos das partes com o uso de letras maiúsculas e em negrito e títulos das atividades apenas em negrito.

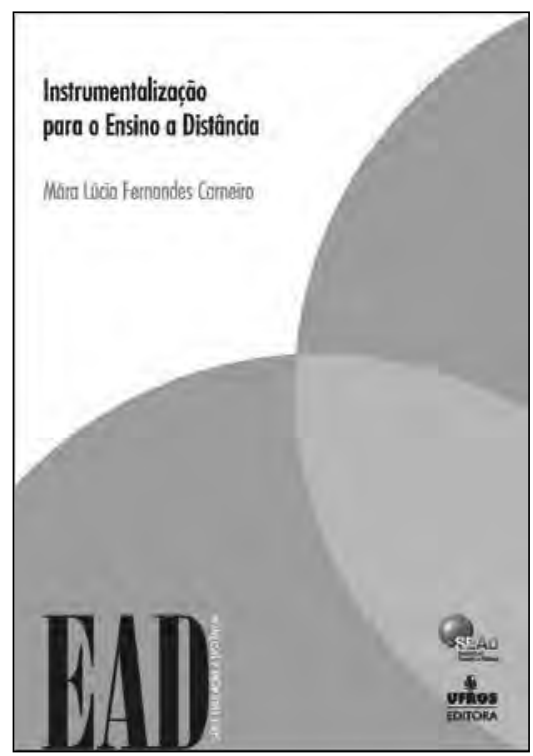

Figura 7. Material C (capa)

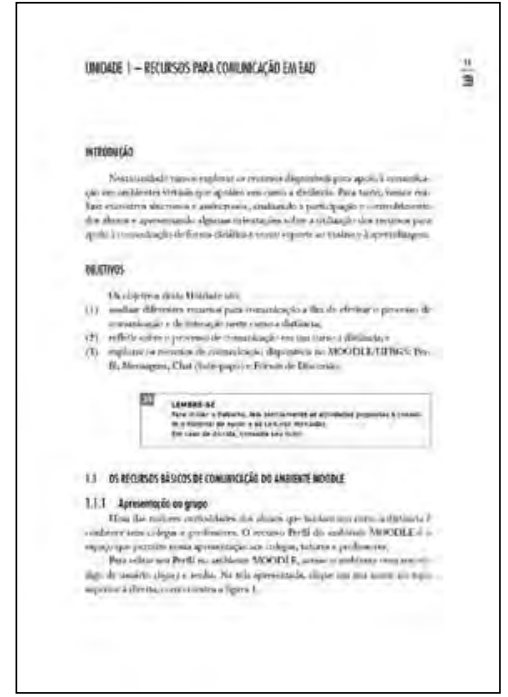

Figura 8. Material C (página inicial de unidade)

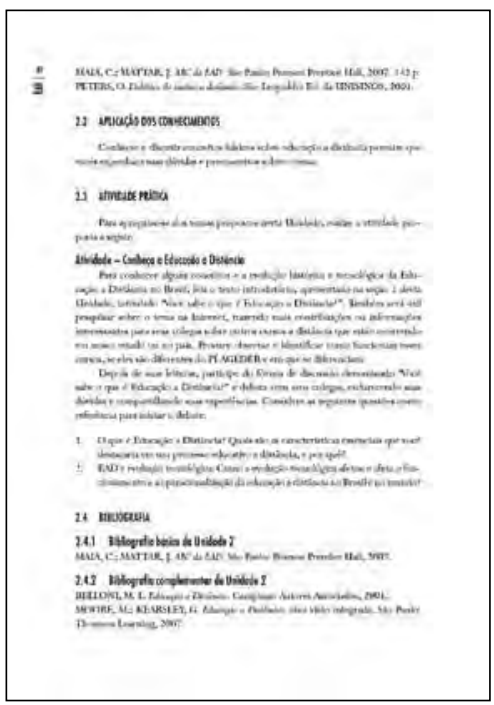

Figura 9. Material C (página aleatória)

\section{Comentários acerca dos materiais}

Referências que discutem a editoração de publicações, de um modo geral, apresentam aspectos válidos para qualquer tipo de produção, por isso, buscar apoio teórico para compreender os materiais analisados exigiu a busca por autores que debatem de aspectos de editoração e, não específicos de produções didáticas, contudo, são referenciais que estão consolidados a tempos nas sociedades. Collaro (2002), ao tratar acerca do projeto gráfico aponta algumas partes, por ele consideradas elementares, no que concerne a produção gráfica de livros. Nelas estão elencadas, entre outras, a capa, página com ficha catalográfica, introdução, miolo, índice. No que diz respeito às partes que estruturam os materiais, notou-se a presença recorrente da capa, considerada fundamental para o encantamento do leitor conforme Collaro (2002), White (2006) e Lidwell, Holden e Butler (2010). Nota-se também a constante de um texto introdutório que apresenta a disciplina ao leitor, o miolo (corpo do texto) organizado em partes distintas, dentre elas, são recorrentes as unidades e atividades. Outro elemento comum nos materiais observados é a ficha catalográfica com registro de 
International Standard Book Number (ISBN), preocupação constante quando se trata de publicações impressas. Um elemento que aparece em dois (02) dos materiais (B e C) é o sumário, também citado por Collaro (2002), no entanto, é válido considerar, aqui, o mapa conceitual, presente no material $\mathrm{A}$, no qual aparecem os tópicos debatidos ao longo do material e possui função semelhante a um sumário. Acerca do sumário e dos textos introdutórios, Lidwell, Holden e Butler (2010) e White (2006) alertam que tais aspectos constituem-se em organizadores prévios para o leitor, preparando-o para a leitura. Além deste é também presente em dois dos materiais as referências bibliográficas, não citadas por Collaro (idem), contudo, comuns em produções desenvolvidas no âmbito acadêmico.

Especificamente com relação à editoração das páginas notam-se alguns elementos recorrentes. Um olhar sobre as capas dos materiais possibilita atentar para a presença do título e autoria dos materiais, a presença da instituição e a composição visual de fundo com o uso de formas geometrizadas e a utilização de uma única cor em suas diferentes tonalidades. Já nas páginas de miolo (texto), notou-se, como constante, o número de página como referência de localização no material, o uso do termo "unidade" como elemento de divisão e organização do texto e a sua presença no início de cada uma das partes. O uso de negrito, assim como o uso de letras maiúsculas para ressaltar títulos também é constante. Um elemento interessante são as imagens icônicas, utilizadas de modo repetitivo para atentar à uma determinada informação, elemento presente em dois dos materiais (A e B) analisados, Lidwell, Holden e Butler (2010) alertam que o uso de figuras icônicas no texto agiliza o processo de leitura e auxilia na memorização e na busca da informação. Observou-se também a presença de boxes e/ou fios para destacar partes, do texto, para as quais o autor chama e ressalta parte da informação, tais elementos são citados por Lidwell, Holden e Butler (2010) e White (2006) como elemento interessante de serem usados quando se pretende chamar a atenção para uma determinada parte do texto. É interessante atentar para o conjunto de retângulos, aqui denominado menu, que aparece apenas em um material (A). Tal elemento constitui-se em um menu de hiperlinks quando o material é apresentado em outro formato, ao qual não se teve acesso, especifico para ser utilizado com o uso de internet.

\section{Comentários finais}

O uso de materiais didáticos no ensino superior brasileiro mostrou um crescimento e evidência com a oferta de cursos na modalidade a distância. Quase já se passaram duas décadas desde as primeiras edições, mas muitas instituições ainda estão engatinhando com as práticas em EAD. Diante disso, muitos materiais utilizados neste contexto ainda se caracterizam pela digitalização de obras impressas, contudo, a necessidade de apresentar textos didáticos e atraentes e efetivos, fez com que algumas instituições desenvolvessem materiais para a oferta de seus cursos. O tema, materiais didáticos para EAD, não ficou apenas no âmbito de produção, tornou-se campo de investigação ampliando, assim, sua concepção e possibilitando o aumento de materiais e objetos de cunho pedagógico, podendo estar entre eles os vídeos, áudios, jogos, imagens etc. Porém, o elemento textual verbal aparece como constante e elementar, por isso, é válido pensar nos modos de como apresentar estes textos de modo que sejam também efetivos, em sua função didática.

Um olhar, restrito, sobre três (03) produtos nos apresenta alguns elementos recorrentes que apontam ser básicos quando se trata de editoração e estruturação de materiais didáticos para a EAD. Observaram-se a preocupação com a informação sobre instituição, disciplina e autoria, bem como o registro desta, aspectos presentes em qualquer publicação impressa. Além disso, ressaltam-se a importância em dividir os conteúdos textuais em unidades e estas em partes com parágrafos de texto, imagens, boxes, atividades. Um aspecto, não recorrente, porém interessante e merece destaque é apresentado em um material (A), o menu, constante em todas as páginas do material correspondente apresenta a preocupação em manter o aluno localizado e com possibilidade de fácil locomoção no material.

Ressalta-se que os materiais observados foram desenvolvidos, todos, em versões impressas e dois deles convertidos em versões digitais em formato PDF, contudo as características observadas nos materiais se apresentam bastante semelhança com produções impressas e, de fato, são materiais impressos. No entanto a sua versão, idêntica, digital pode ser complicada de ser lida em meios tecnológicos como computadores, tablets, entre outros utilizados nos processos da EAD. Diante das observações, nota-se a necessidade de buscar, ainda mais, encontrar especificidades que necessitam compor o layout de materiais didáticos para EAD de modo que potencializem as aprendizagens.

\section{Referências}

Brennand, E. \& Rossi, S. (2007). Trilhas do Aprendente. v. 1. Recife: Liceu.

Colaro, A. C. (2000). Projeto Gráfico: teoria e prática da diagramação. São Paulo, Summus.

Illera, J. L. R. (2010). Os conteúdos em ambientes virtuais: organização, códigos e formatos de representação. In Coll, C.; Monereo, C. (Orgs) (2010). Psicologia da Educação Virtual: aprender e ensinar com as tecnologias da informação e da comunicação. Trad. Naila de Freitas. Porto Alegre: Artmed.

Lidwell, W.; Holden, K., \& Butler, J. (2010). Princípios universais do design. Porto Alegre, Bookman.

SEAD/UFRGS. (2017). Curso de Graduação Tecnológica - Planejamento e Gestão para o Desenvolvimento Rural da SEAD/UFRGS (PLAGEDER) - material didático. (Série Educação A Distância). Porto Alegre, Editora da UFRGS.

Silva, M. G. S. (2007). Psicologia e educação: livro didático. Palhoça, UnisulVirtual.

White, J. V. (2006). Edição e design: para designers, diretores de arte e editores. São Paulo: JSN Editores. 